\title{
A Magnificent Blond Beast: \\ Exploring the Implications of Harlem Renaissance \\ Writer Wallace Thurman \\ as Ghostwriter of a Forgotten Celebrity Gossip Memoir
}

\begin{abstract}
In an early version of his article "Harlem Literati in the Twenties," first published in the Saturday Evening Review in 1940, Langston Hughes offers the curious suggestion that Wallace Thurman was the ghostwriter of Men, Marriage and Me (erroneously written as Men, Women and Checks in Hughes' article), the tell-all memoir ostensibly by the original blonde bombshell Peggy Hopkins Joyce. According to Hopkins' biographer, however, Basil Woon, an English playwright and gossip columnist was supposed to have been the ghostwriter of this book. My paper will address this discrepancy by focusing on the lack of evidence supporting the Woon theory, and through an analysis using stylometry, close reading and an examination of historical documents, I will argue that Thurman is the more likely candidate as a ghostwriter for Hopkins' memoirs, just as Hughes suggests. I will be looking specifically at the way the text, which is presented to the reader as a diary written by Hopkins from her early youth to the present day, satirizes the shallowness and excesses of the "roaring twenties." I will argue that the text is clearly ironic and satirical in style and approach and not only satirizes celebrity, but also a society that unselfconsciously celebrates celebrity, much the way Thurman satirizes the excesses of the Harlem Renaissance in his novel Infants of the Spring. In conclusion, I will show how this book, which has been largely dismissed as celebrity gossip, is transformed into something highly literary by the way Thurman, as ghostwriter and editor, takes Hopkins' life story and turns it into a satire of the excesses of an era.
\end{abstract}

Keywords: Wallace Thurman, Harlem Renaissance, Peggy Hopkins Joyce, satire, stylometry, author attribution, Friedrich Nietzsche, Langston Hughes, Basil Woon, the jazz age

This literary riddle begins with an obscure early version of a fairly well-known essay by Langston Hughes. The article, "Harlem Literati in the Twenties," first appeared in the Saturday Evening Review in the June 22, 1940 issue. In this issue, Hughes writes, referring to his friend and Harlem Renaissance editor and writer Wallace Thurman, "[i]t has been said that he wrote blonde Peggy Hopkins Joyce's, "Men, Women and Checks'" (13). By the time this article appears again, this time in Hughes' celebrated memoir, The Big Sea, which also appeared in 1940, the text had been revised to read, "[i]n fact, this quite dark young Negro is said to have written Men, Women and Checks" (234). By leaving out the name of Peggy Hopkins Joyce in the book version, Hughes further obscures the referenced text itself, as Peggy Hopkins Joyce's memoir was actually called, Men, Marriage and Me, thus making it easy to dismiss the claim when the book itself can not be easily identified. As it turns out, however, the implications for Wallace Thurman having written Peggy Hopkins Joyce's memoir, or having ghostwritten the memoir are fairly important, and if we can add this book to the canon of Harlem Renaissance productions, it adds another interesting aspect to the work and thought of the Harlem Renaissance writers. The 
book, when viewed through the lens of Thurman's pen, becomes a biting satire of American consumer and celebrity culture, which was just coming into its own, with Peggy Hopkins Joyce as the first example of a celebrity being famous for no particular skill other than being a well-known socialite and tabloid celebrity.

\section{Who Was Peggy Hopkins Joyce?}

Peggy Hopkins Joyce is not very well-known today, but in the 1920s and 1930s, her name would have been known throughout almost every household in the United States. Peggy Hopkins Joyce's biographer, Constance Rosenblum writes,

[s] he made headlines not because she triumphed on the silver screen like Mary Pickford, or flew across the Atlantic alone like Amelia Earhart, or swam the English Channel like Gertrude Ederle, or helped precipitate a constitutional crisis like Wallis Warfield Simpson, or stood at the center of a sensational crime like Evelyn Nesbit, or nestled under the wing of a powerful media baron like Marion Davies, or was anointed debutante of the year like Brenda Frazier. She did nothing of significance except collect and discard rich husbands in rapid succession in an age when such behavior was severely frowned on. The husbands themselves were nothing special; what little fame they accrued came solely from having their names linked with hers.

In lieu of real accomplishments, however, Peggy had something far more important, the almost undivided attention of the newly powerful mass media, and over a remarkably long period. Her entrance onto the national stage was providential: she appeared just as the tabloid newspaper was poised to reshape American society, and the two had a perfect symbiotic relationship. She made a name for herself simply because they put her name in the papers; she was blasted into public prominence entirely by way of the screaming headline, the grainy tabloid photo, the frantic, dot-dot-dot item in the gossip column. She was a product of technology; she and Jazz Age journalism were born for each other, and they used each other shamelessly and with equal abandon." (Gold Digger 4-5)

This long introduction to Peggy Hopkins Joyce is to give a sense of the time in which she lived, and her relationship to those times, especially as her presence presaged a new development in American pop culture, and American consumer culture. The kind of flamboyant excess she represented, as the original "Gold Digger of Broadway," spoke volumes not only to the changing relationship women had to the culture, but also to the culture itself, and the culture's relationship with wealth, celebrity, journalism and entertainment.

For example, as a figure of female empowerment, Harlem Renaissance luminary Zora Neale Hurston seems to have seen something of interest in the rise of Peggy Hopkins Joyce. In her essay, "How it Feels to be Colored Me," Hurston writes, "Peggy Hopkins Joyce on the Boule Mich with her gorgeous raiment, stately carriage, knees knocking together in a most aristocratic manner, has nothing on me. The cosmic Zora emerges. I belong to no race nor time. I am the eternal feminine with its string of beads" (216). Peggy Hopkins Joyce also makes an appearance in Bruce Nugent's story, "Smoke, Lilies and Jade," in which she is spotted at a jazz club, Forno's,: "oh her cousin was with them and Peggy 
Joyce... everyone came to Forno's..." (38). So, Peggy Hopkins Joyce certainly had captured the imagination of not just mainstream America, but also the relatively avant-garde younger writers of the Harlem Renaissance as well. Concerned as they were with critiquing contemporary society, it should come as no surprise that the writers of the Harlem Renaissance took the time to comment on such aspects of American society as celebrity culture, especially given the developing relationship white American pop culture had to African American folk culture during the socalled Jazz-Era.

Peggy Hopkins Joyce's memoir Men, Marriage and Me appeared in 1930. That it was ghostwritten was never much in doubt. ${ }^{1}$ The question that arises then is: who ghostwrote the text? Rosenblum writes in her biography of Peggy Hopkins Joyce, "[i]n 1929, the New York firm of Macaulay and Company contracted with Basil Woon, an English journalist and travel writer with a flair for waxing poetic about the sophisticates of Hollywood and Europe, to help Peggy tell her story" (206). Thus, it would seem that Basil Woon was the ghostwriter for Hopkins Joyce's memoirs, especially as Rosenblum suggests that he would also later be contracted to ghostwrite her second book (Gold Digger 213). However, it appears that Basil Woon did not actually ghostwrite the second book when one checks the records of Macauley, the publisher. There one finds that Transatlantic Wife, Peggy Hopkins Joyce's second book (a novel this time), was ghostwritten by Maurice Dekobra, a prolific French novelist from the 1920s and 1930s (Macauley Special Records, https://library.osu.edu/ $)^{2}$. Thus, the question as to whether Woon ghostwrote Men, Marriage and Me is an open question.

In order to investigate the issue, I wrote to Rosenblum, to see if she had obtained official information unambiguously declaring Woon to be the ghostwriter of the memoir. Rosenblum kindly wrote me back with the following message:

In my research, which was now a long time ago, I don't recall ever having come across a Wallace Thurman, and my knowledge about Basil Woon's role came, as I remember, from newspapers articles and reviews of the book. I also suspect that since publishing was a far more casual affair back then, there weren't many contracts floating about, and those that existed were casual affairs - especially for inconseqential works such as Peggy's "memoirs" - in any case, I never saw one. (Personal correspondence)

This leaves the question open: was Basil Woon really the ghostwriter of Peggy Hopkins Joyce's memoirs, or was it Wallace Thurman, as Langston Hughes

1 Peggy Hopkins Joyce claims in the Brooklyn Daily Eagle that she wrote the book herself - that it is indeed her diary, written faithfully since she was fifteen years old; although she admits that there is fiction in the manuscript as well (19). However, as the reviewer in the article hints at, most celebrity memoirs were ghostwritten at the time, and Peggy Hopkins Joyce's would have been no exception. There is also the additional issue of the voice of the unidentified editor in the memoir, who comments throughout at the beginning of some of the chapters on Peggy Hopkins Joyce's development, and guides the reader's interpretation of the text, giving the book the stylized feel of a self-consciously written narrative, and not the haphazard diary it purports to be.

2 This reference probably would not have been available to Rosenblum in 2000 when she was writing her biography. 
suggests? Since the paper trail apparently ends here, I only had two means of going forward with the inquiry: one was to do a digital analysis of the text, and attempt to determine if the style matched up with Thurman or Woon's style, and the second would be to do a traditional analysis of the text, and try to determine from stylistic and thematic preoccupations, if the author of the text could be ascertained. The remainder of this paper will track the results of each of these approaches.

\section{A Digital Analysis of the Text: The Corpus}

Analyzing the text digitally presented several challenges. The first was procuring a digital copy of the text. The book is out-of-print, and certainly no e-book of the text exists. That meant that I had to purchase a facsimile copy of the book from an online distributor, scan the book in, and then correct the OCR. This timeconsuming process was just the first in a series of steps needed to analyze the text. In order to get a good sense of how the book's style stood in comparison to other books of the era, I assembled a corpus of forty-two additional texts, all published between the years 1920 and 1940 (taking into consideration the 1930 publication date of Men, Marriage and $\mathrm{Me})^{3}$. One of those forty-two texts was, of necessity, Gentlemen Prefer Blondes by Anita Loos, published in 1925. This is because both Constance Rosenblum (Gold Digger 155) and Loos scholar Cari Beauchamp (46) suggest that the character Lorelei Lee in Gentlemen Prefer Blondes was modeled after Peggy Hopkins Joyce. I have also included the sequel to Gentlemen Prefer Blondes as an additional control, a novel called But Gentlemen Marry Brunettes, which was published two years later, in 1927. One additional text I would have liked to include in the study, but was unable to obtain the digital text for was Transatlantic Wife, Hopkins' second book, although the authorship of that book cannot really be said to be in dispute given the Macauley records.

I have also used three books by Basil Woon as a control, Arizona's Yesterday, a memoir co-written with John Henry Cady, the memoirist; Woon's best-known book, another memoir written in tandem with the memoirist, Sarah Bernhardt as I Knew Her: The Memoirs of Madame Pierre Berton as Told to Basil Woon; and Woon's own account of his experiences in Cuba, When It's Cocktail Time in Cuba. One problem that arose from choosing texts by Woon is that he did not write novels, at least not in his own name. Thus, I chose three books that seemed to be in the spirit of the enterprise: one book I chose by him falls outside the year range, as it was published in 1915, but has the benefit of being the memoirs of John H. Cady as rewritten by Basil Woon, giving us a concrete demonstration of how Woon would have "ghostwritten" a memoir; the second book, Madame Pierre Berton's memoirs of Sarah Bernhardt, fulfills a similar function. The third book I selected by him, When It's Cocktail Time in Cuba is a memoir of sorts of his own experiences traveling through Cuba. Thus, these three books, while not novels, are memoirs and seem to fit the spirit of the project.

3 With the one exception of Basil Woon's 1915 Arizona's Yesterday co-written with John Henry Cady. 
I used the two novels Wallace Thurman wrote as well ${ }^{4}$. The other novels in the corpus come from classic works of fiction by Harlem Renaissance luminaries, classic "jazz-age" authors, and books that appeared on bestseller lists during those twenty years. The resultant corpus is thus diverse in terms of race, gender and age. Furthermore, I have included two actual memoirs in the corpus, The Autobiography of Margot Asquith, and Edward Bok's Pulitzer Prize winning, The Americanization of Edward Bok, to make a control for genre, and make sure that the format of Men, Marriage and Me wasn't interfering with the accuracy of the results. However, due to the fact that the book was ghostwritten, and that Peggy Hopkins Joyce described it as a work of both fiction and fact, pairing it for the most part with novels seemed to be the sensible approach.

I have also included two texts by Maurice Dekobra, the ghostwriter of Transatlantic Wife, Peggy Hopkins Joyce's second book. This in itself presented a few challenges. The reason for this is that Macauley, the publishing house that published Men, Marriage and Me as well as Dekobra's English language books, was both a French and English-language publisher, and it appears that Transatlantic Wife, Peggy Hopkins Joyce's second book, was ghostwritten by Dekobra in French, and then translated by an unnamed party into English (Macauley Special Records, https://library.osu.edu/). Thus, when deciding which texts by Dekobra to choose, I decided to choose two texts by a translator who had been translating Dekobra's French language novels into English for Macauley around the exact same years Transatlantic Wife appeared, Metcalfe Wood. A full list of the books that appear in the corpus can be found as an appendix to this article.

\section{A Digital Analysis of the Text: Method}

The next question that arose was which method to use when digitally analyzing the corpus in order to determine author attribution. This required me to look into author attribution software currently in use in the field of Digital Humanities. Digital Humanities is a field of research that is interested in new means of examining texts that go beyond "close reading," instead doing a style of textual analysis known as "distant reading" (Moretti) or "macroanalysis" (Jockers). This type of analysis involves taking large numbers of texts - in this case, what I have identified as my corpus of forty-three books - and scanning the texts digitally, in order to pinpoint similarities of style between texts in the corpus. Two recent cases of author attribution have gained considerable international attention because of the high profile of the authors and works with which they were concerned. The first of these cases involved a novel called The Cuckoo's Calling, ostensibly written by someone named Robert Galbraithe, and published in 2013. It was later revealed that J.K. Rowling, who famously wrote the Harry Potter, series was the actual author of the novel. This fact was determined by the work of researchers Peter Millican of Oxford University and Patrick Juola of Duquesne University, who analyzed the text using an approach known as "linguistic stylometry." As Joula writes: "The

4 Thurman co-wrote a third novel, The Interne, however this book I have not included, being a cowritten novel, and not a memoir, as in the case of the co-written books by Woon. 
basic theory [of stylometry] is pretty simple: language is a set of choices, and speakers and writers tend to fall into habitual, or at least common, choices ... But what we do know is that much of this apparently free variation is actually rather static at least at an individual level. So by studying examples of documents a person has written, we can build a model of the kind of choices that person makes" (https://languagelog.ldc.upenn.edu).

The second high profile case involved a 2015 study of To Kill a Mockingbird and Go Set a Watchman, conducted by Jan Rybicki and Maciej Eder. This analysis set out to settle the dispute as to whether or not Harper Lee had written the novel Go Set a Watchmen, the controversial novel which was published earlier that year. In their final analysis they determined that the novel had indeed been written by Harper Lee (https://www.wsj.com). This analysis also used stylometry. For this reason, I decided to use the same methodological approach as these two highprofile and highly successful and influential examples.

When using R, the stylometric software used in these two previous cases, one has to set parameters for analysis. Perhaps the most important of those is the search for Most Frequent Words (MFW), as this is highly indicative of style (Joula). This I set at the parameters of 100-3000, with increments of 50 for what is known as a Bootstrap Consensus Tree (BCT) (See Figure 1). I used this setting because it follows those used by the researchers in the previous high-profile cases, is the default setting for the program, and thus seemed to be a logical approach for a standard author attribution analysis, as I had no reason to alter these defaults specific to my analysis. The resulting BCT can be seen in Figure 1.

\section{Bootstrap Consensus Tree}

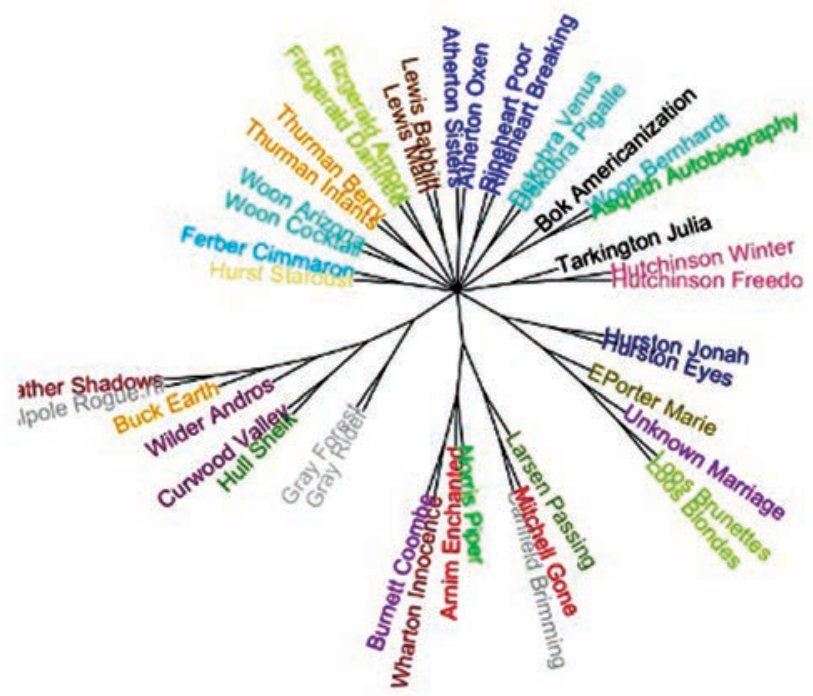

100-3000 MFW Culled @ 0\%

Classic Delta distance Consensus 0.5

Figure 1: Bootstrap Consensus Tree analysis of corpus. 
One sees that Men, Marriage and Me ("Unknown Marriage") pairs with Anita Loos Gentlemen Prefer Blondes (Loos_Blondes) as well as with But Gentlemen Marry Brunettes (Loos_Brunettes), but does not pair with either Thurman or Woon.

Thus I conducted another test, known as a Cluster Analysis (CA), which shows a hierarchical analysis of the most frequently used words. I ran two CA's,: one analyzing the hundred most frequent words used, as well as one analyzing the 1,500 most frequent words. They returned similar results (see Figures 2 and 3).

\section{Cluster Analysis}

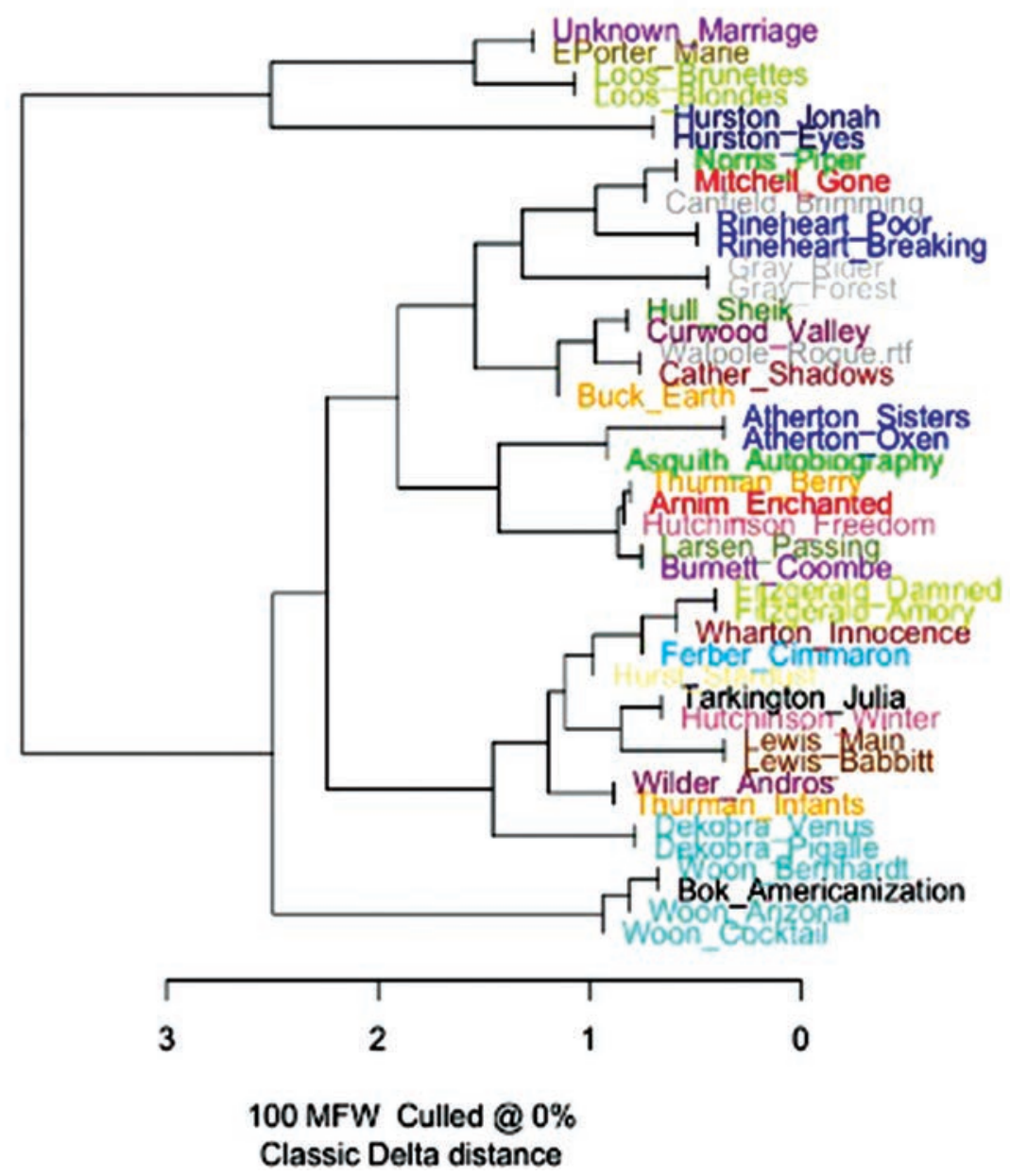

Figure 2: Cluster Analysis of corpus at $100 \mathrm{MFW}$ 


\section{Cluster Analysis}

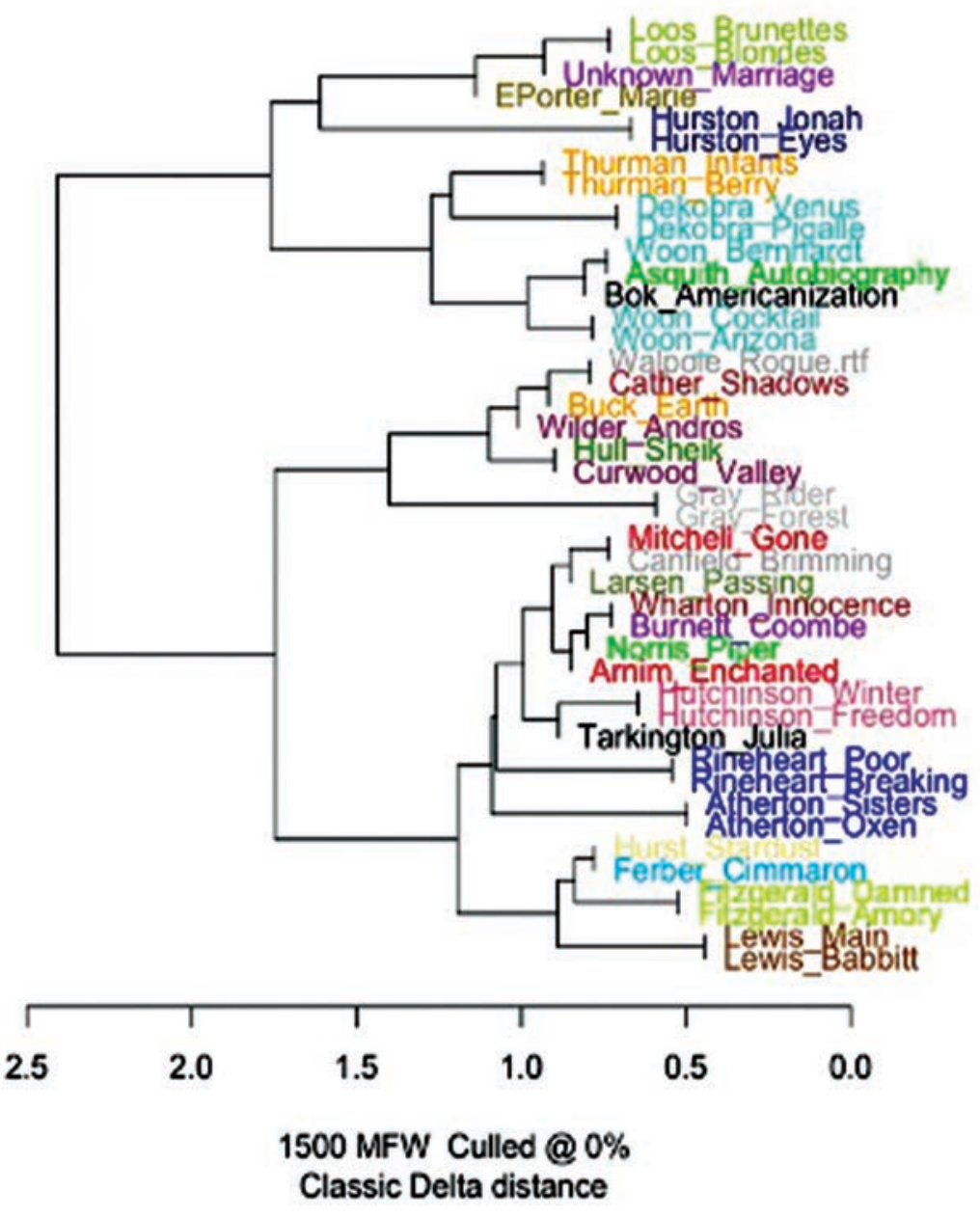

Figure 3: Cluster Analysis of corpus at $1500 \mathrm{MFW}$

The controls seem to work well, especially with the CA set to 1,500 MFW, as most authors' books are paired reliably together. For our purposes, there is nothing here to suggest that either Woon or Thurman wrote Peggy Hopkins Joyce's memoirs; indeed, the evidence strongly seems to suggest that Anita Loos ghostwrote the memoir herself! It is useful to remember that Anita Loos' Lorelei Lei in Gentlemen Prefer Blondes was widely considered to be based on Peggy Hopkins Joyce. Thus the evidence here points to one of two possible conclusions: either Anita Loos ghostwrote Peggy Hopkins Joyce's memoirs herself, or whoever ghostwrote the memoirs did so in a manner intended to mimic Anita Loos' Gentlemen Prefer Blondes, and was wildly successful in the venture. 


\section{Anita Loos as Author of Peggy Hopkins Joyce's Memoirs}

The first area of investigation has to start with Anita Loos, since the digital analysis strongly suggests that she is indeed the author of Men, Marriage and Me. It is my contention that it is highly unlikely that Anita Loos would have ghostwritten Peggy Hopkins Joyce's memoirs. The first reason for this is that Anita Loos simply did not think much of Peggy Hopkins Joyce. Constance Rosenblum writes of Anita Loos, "in her opinion Peggy ranked as the most shameless of such kept women. The acid-tongued Loos liked to point out that Peggy enjoyed a brief stint as the mistress of Hollywood producer Joe Schenck before he settled down with the actress Norma Talmadge and began his climb to the top of Twentieth CenturyFox" (Gold Digger 60-61).

Secondly, in 1929, when Men, Marriage and Me would have most likely been written, Anita Loos was traveling, first in New York and Palm Beach, and later in London and Paris, a period which she would refer to later as her "wasted years" (Carey 133-134). It seems unlikely that she would have been engaged with the ghostwriting of Peggy Hopkins Joyce's memoirs during this period, especially considering the 1928 release of the film version of Gentlemen Prefer Blondes, and the financial success that would have brought her.

Finally, there is nothing on record to show that Loos had any association with Macauley Publishing Company - she appears in none of their contract papers, she never published with them and she was never known to be associated with them in any way. Loos' publisher during these years was Boni \& Liveright, and Loos ghostwriting a book for Peggy Hopkins Joyce for Macauley in the years directly following her publication of Gentlemen Prefer Blondes (especially considering the fact that it had become a major motion picture in 1928, starring Marilyn Monroe) would most likely have violated contractual agreements, not to mention basic norms of decency in author-publisher relations. Thus, I again maintain that it is highly unlikely that Anita Loos, never known to be a ghostwriter to any degree, ghostwrote Peggy Hopkins Joyce's memoirs.

\section{Basil Woon as Author of Peggy Hopkins Joyce's Memoirs}

As we have noted, Basil Woon was also a possible ghostwriter for Peggy Hopkins Joyce. While it is fair to say based on the Macauley Publishing Company papers that Basil Woon did not ghostwrite Transatlantic Wife, the question of Men, Marriage and Me is still open. As we have also noted, Peggy Hopkins Joyce's biographer, Constance Rosenblum did not have any definitive evidence that Basil Woon was the ghostwriter. However, since it seems that he has been named by some as a ghostwriter, and as he did ghostwrite books for other authors, it is best to take the suggestion seriously.

The first suggestion that Woon may have ghostwritten the memoirs comes from Basil Woon's obituary in the New York Times. Here we find written,: "He also had been a correspondent in Paris, a publicity man for Cuba and a ghost writer for Peggy Hopkins Joyce" ("Basil Woon" nytimes.com). The article does not specify 
what he may have ghostwritten, or when. Is his ghostwriting limited to the weekly "How to Get Your Man" columns that Peggy Hopkins Joyce published in the Evening Graphic, or did they extend beyond that? Indeed, what evidence is there that Woon ghostwrote anything for Peggy Hopkins Joyce at all? The New York Times does not list any sources. The only other hint that Basil Woon might have ghostwritten the book one finds in the Brooklyn Daily Eagle, from Monday, February 17, 1930. Here one reads in the gossip column, "The Week of a New Yorker" the following: "To make another attempt at Peggy Hopkins Joyce's 'Men, Marriage and Me,' which one would have to resort to pig latin [sic] to describe and to give it up as all hooey and a yard thick, wondering if there was any truth in the rumor that the tome was ghost-written by Basil Woon" (21). This is to say that there was certainly rumor and hearsay that Basil Woon was the ghostwriter, but how much authority we can attribute to this humorous gossip column is a question worth asking.

Included in the corpus there are two books by Woon that are acknowledged to be "ghostwritten" (or more accurately, co-written) by him: one by John Cady, and the other by Madame Pierre Berton, and her recollections of Sarah Bernhardt (perhaps Woon's most famous book). Both of these books line up nicely with Woon's own personal account of his life in Cuba in the digital analysis, and yet Woon's books appear to have nothing to do with Peggy Hopkins Joyce's book. Furthermore, there is no mention that Woon had any connection to Macauley as a publisher anywhere except in Rosenbaum's book. Indeed, Woon's memoirs of Cuba are published by Boni \& Liveright, Anita Loo's publisher. Thus, given the lack of connection between Macauley and Woon, and given the fact that other books "ghostwritten" by Woon smack of his individual style (according to the digital analysis), it seems unlikely that Woon was the writer of Peggy Hopkins Joyce's memoirs. The more likely explanation is that this rumor, having been first reported in the press, was subsequently taken as fact.

\section{Making the Case for Wallace Thurman as Author of Peggy Hopkins Joyce's Memoirs}

This leaves the final possibility: namely that Wallace Thurman, whom Thurman's friend and colleague Langston Hughes claimed was the actual ghostwriter of Men, Marriage and $M e$, did indeed write the memoirs. From a glance at the digital analysis, this would seem to be unlikely. While Thurman is positioned closer to Men, Marriage and Me than Woon's texts are in the 1500 MFW Cluster Analysis (Fig. 3), the proximity is not enough to be conclusive. In fact, the only books that are consistently paired with Men, Marriage and Me are Anita Loos' two novels; so once again we have to accept that either Loos wrote the book herself, which (as has been determined), is unlikely, or it will be necessary to look at other aspects of the text that might give clues as to who the true author might have been.

The biggest obvious difference between Thurman and the other two authors offered here as possible ghostwriters is the relationship the authors had with the publisher of Peggy Hopkins Joyce's memoir, Macaulay. All three of Wallace Thurman's novels were published by the Macaulay Company: The Blacker the 
Berry in 1929, Infants of the Spring in 1932 and The Interne, written with A.L. Furman ("a lawyer and family member of one of the Macaulay publishers" [van Notten 254]) in 1932. Furthermore, Thurman did not just publish with Macaulay, he played (surprisingly enough for an African American at this time) an important editorial role as well. As Thurman biographer Eleonore van Notten writes, "[i]n September 1932 an announcement appeared in The Crisis reporting that Thurman had been appointed editor-in-chief of the Macaulay Company following his recent publication of The Interne" (295). Prior to that Thurman had worked as a reader at the company, although the details of his duties are not exactly clear. As van Notten writes, "[f]ew records remain to document Thurman's activities at the Macaulay Company. From Dorothy West's account it would appear that Thurman's work centered mainly on the publication of 'popular fiction.' West explains that Thurman's experience at True Story magazine made him eminently suitable for this position" (296). This reference to True Story magazine draws us deeper into the mystery. As early as 1928 Wallace Thurman was ghostwriting stories for True Story magazine through Macfadden Publishing (Singh xviii). True Story was a magazine that published sensationalistic true-life stories (or so they were purported to be in any case). It is reasonable to assume that at some point in 1929, while Thurman was working out the details of publishing his first novel with Macaulay, that he established a deal with the publisher to ghostwrite Peggy Hopkins Joyce's sensationalist true-story memoir as well. It would, in fact, have been right in line with the editorial work he was already doing.

The case for Wallace Thurman becomes even stronger when one looks at the text of Peggy Hopkins Joyce's memoir itself. The book is certainly written as a satire, regardless who wrote it, and much of the wit of the book comes from the intentional dramatic irony established between what the reader understands and what the author of the diary relates. This is especially true in the early parts of the book when Hopkins Joyce is still young and naïve. One sees this even in the chapter titles; for example, chapter two is titled, "I became a Wife - For Two Days," which of course is meant to elicit a chuckle from the reader who knows Peggy Hopkins Joyce to have been married numerous times to various wealthy men. The marriage runs into problems when her husband attempts to consummate their relationship: "He said, dear, that is an experience every wife has to go through, you are just young that is all and when you think it over you will know that I love you and you will come back to me" (30). Peggy swears off men altogether, but of course within a few chapters she is married again, this time to Sherburne P. Hopkins, another millionaire. "After all Sherby is a Millionaire and very prominent socially and a girl cannot marry a Millionaire who is prominent socially every day" (51). By chapter seven, she leaves Sherburne, after having established herself in society: "I did not take his presents with me when I left, except the wrist-watch which I needed. I put them on the dressing-table where he could see them and I took only eight dollars in cash because I would not ask him for money to leave him with, and I only took a few of my dresses, just one suitcase" (71). This approach to satire is exactly the type of "Modernist Burlesque" that Dickson-Carr reveals to be central to many of the Harlem Renaissance writers' approach to satire: 
Schuyler, Thurman, Hurston, Fisher, Nugent, and others engage in what Sonnet Retman calls "modernist burlesque, a kind of satire that occupies its subject from the outside in by pushing its most theatrical and technological elements to spectacular excess." Modernist burlesque seeks to "dismantle the authentic aura" surrounding the folk or the masses, to question whether authenticity of any sort resides only in the imagination, thriving in cultural arbiters more concerned with controlling or speaking for the folk and their cultural products rather than allowing them to speak. Modernist burlesque is perhaps akin to reductio ad absurdum, the rhetorical technique central to countless satires. Reductio ad absurdum - reduction to the absurd - takes a particular figure or institution's most emblematically lamentable qualities, discards nuances and complexities, and reveals the falsehoods, exaggerations, and puffery at the heart of the satiric target. (18-19)

This is the exact approach to satire taken in Peggy Hopkins Joyce's memoir. It takes the character of Peggy Hopkins Joyce, and through a distinct lack of nuance and complexity, reveals through dramatic irony how profoundly shallow and materialistic her worldview is.

Another interesting aspect of Peggy Hopkins Joyce's memoir is that, while written like a series of diary entries, these entries are interspersed with commentary from the editor, who is almost certainly the same person as the ghostwriter, given the narrative symbiosis between what the editor announces is to come, and the text that follows. Moroever, the editor doesn't comment on Peggy Hopkins Joyce's absurdities, or the obviously intentional ironies in the text. On the contrary, the editor plays the role of something like stage manager, adding narrative where narrative is missing, and takes her account completely at face value. For example, at the start of chapter four, the chapter in which she meets Sherburne, the editor begins the chapter with the following commentary: "Note also the influence her experience and her two months' schooling have had on the young girl's writing. Through the inconsequential phraseology of the child we begin to discern the tremulous, uncertain, at times chaotic reasoning of adolescence" (35).

This commentary follows Peggy Hopkins Joyce throughout the book, and provides a meta-narrative in which Peggy Hopkins Joyce undergoes something of a spiritual transformation that occurs despite the fact that she has spent the entire book in pursuit of material goods through marriage. This is most evident in chapter twenty-four, when she goes through with her divorce from Stanley Joyce, the man who gives her her last name. In this chapter we find the following passage:

It's time to be honest with myself. I expect I have always found it hard to be honest with myself. Most people do.

I'm not sure that I'm any more selfish than other people, really. When you come to figure people out everybody is after happiness and the thing that will give them the most satisfaction. Even people who are known as being very unselfish are that way because they have learned that it makes them happier to be. So after all they are really selfish too - giving things to people and doing things for them because they find the most happiness that way. (189) 
This sounds very much like a reiteration of ideas expressed by Nietzsche, in particular Nietzsche's immoralist, who stands beyond good and evil. This is important because Wallace Thurman considered himself to be a "confirmed Nietzschean" (Thurman, Collected Writings 235). Nietzsche writes:

We immoralists!.-This world with which we are concerned, in which we have to fear and love, this almost invisible, inaudible world of delicate command and delicate obedience, a world of "almost" in every respect, captious, insidious, sharp, and tender - yes, it is well protected from clumsy spectators and familiar curiosity! We are woven into a strong net and garment of duties, and cannot disengage ourselves - precisely here, we are "men of duty," even we! Occasionally, it is true, we dance in our "chains" and betwixt our "swords"; it is none the less true that more often we gnash our teeth under the circumstances, and are impatient at the secret hardship of our lot. But do what we will, fools and appearances say of us: "These are men without duty," - we have always fools and appearances against us! (152)

Or, to put it a way that would have been very familiar to Thurman, whose introduction to Nietzsche almost certainly came from his reading of Mencken ${ }^{5}$ :

Nietzsche called himself an immoralist. He believed that all progress depended upon the truth and that the truth could not prevail while men yet enmeshed themselves in a web of gratuitous and senseless laws fashioned by their own hands. He was fond of picturing the ideal immoralist as "a magnificent blond beast" - innocent of "virtue" and "sin" and knowing only "good" and "bad." Instead of a god to guide him, with commandments and the fear of hell, this immoralist would have his own instincts and intelligence. Instead of doing a given thing because the church called it a virtue or the current moral code required it, he would do it because he knew that it would benefit him or his descendants after him. Instead of refraining from a given action because the church denounced it as a sin and the law as a crime, he would avoid it only if he were convinced that the action itself, or its consequences, might work him or his an injury. (Mencken 96-97)

Throughout the course of the book, then, the reader sees Peggy Hopkins Joyce's development from a naïf to a powerful immoralist herself; she has in fact always been this immoralist, she was just not cognizant of the fact until she developed sufficient knowledge of herself (although, as we will see, that knowledge does not go far enough). Thus, at the start of chapter thirty we find the editor writing:

From now on the careful reader will notice a subtle difference in the writings of Peggy in her famous Diary. She is less naïve, less ingenuous, less revealing. This is because she has already contracted for publication of the Diary. She is writing for publication - a vastly different thing than writing for oneself alone.

5 It is also likely that Thurman read Nietzsche himself in translation. To that end, my Nietzsche translation comes from the 1917 Helen Zimmern translation, which would have been available to Thurman. 
Nevertheless, it is in the chapter to follow that some of the most astonishing revelations of Peggy's soul are made. Her comments upon men and life in general constitute a philosophical addition to contemporary satire. Her epigrams become more rounded, but are none the less apt and original.

Peggy as an "author" almost outshines Peggy as Diarist. (233)

This preface is to a chapter in which Peggy Hopkins Joyce is now able to rewrite ten rules given to her early on in the book by model Fanny Brice, and rewrite them in a wittier way; rhe chapter introduces the reader to a much more mature Peggy Hopkins Joyce - one need not be a "careful reader" at all to notice it. The transformation is, in this chapter, complete. Peggy Hopkins Joyce more or less lays out a philosophy of love which is full of witticisms and epigrammatic sayings that are characteristic of the fast-talking, snappy dialogue endemic to the flapper-stereotype: "Some women use all their energy in keeping a husband's good will by flattering him and making him think what a great man he is. This may keep him your husband but it will not keep him your lover"; or "You show me a man with his stomach full of his wife's good cooking and his slippers on the rug and his pipe in his mouth and his newspaper in his hand while his wife sits by sewing, and I will show you a man who is too happy to be in love" (234-235).

Peggy's new cynical flapper philosophy, where she views love as sport in the manner of Hemingway's Lady Brett Ashley, makes her transformation impressive, and yet the satire remains biting until the end. The interjection by the editor at the beginning of chapter thirty, where he remarks on the development and maturation of Peggy Hopkins Joyce is the last we hear from him. Once again, the reader is left with dramatic irony that continues to satirize the emptiness of the materialistic life, despite Peggy's maturation. The final chapters see Peggy courted by a wealthy Italian suitor who turns out to be married, and so the affair ends with her being abandoned and humiliated.

Finally, the book ends with her having met someone new. She writes:

After all that's one of the nice things about life. That no matter how many times you have been disappointed when something nice begins to happen you can have just as much fun expecting.

Perhaps that's childish, but if it is I don't want ever to grow up. Maybe I'm kidding myself a little, but what of it? It's such fun.

I got up this morning, wondering, "Will he call me? Won't he call me?"

That's the sort of thing that makes getting up in the morning worth while. (285-286)

It's a bleak ending, where Peggy Hopkins Joyce has actually not learned anything: Because she hasn't really come to examine her own motivations, she continues to be stuck in her normal patterns of behavior, and any maturation she has done is lost to the fact that she hasn't confronted the fundamental issue that drives her, namely, her empty materialism. For Thurman, true self-knowledge was an essential component of "the will to power." Thurman writes in his own "objective" third-person autobiography, "Notes on a Stepchild:" 
He believes it is the duty of those who have the will to power in artistic and intellectual fields to shake off psychological shackles, deliberately formulate an egoistic philosophy, develop a cosmopolitan perspective, and soar where they may, blaming only themselves if they fail to reach their goal. Individual salvation may prove a more efficacious emancipating agent for his generation and for those following than self-sacrifice or morbid resentment.

There has been in the past far too little of the former and far too much of the latter. The Negro has been so busy bemoaning his fate, so busy placing the entire responsibility for his failures on Marse George that he has not yet stopped to take stock of himself. This volume pretends to be a step in that direction. (234)

Thurman's "egoistic philosophy" requires a knowledge-of-self that Peggy Hopkins Joyce doesn't achieve by the end of her memoir, and so what she perceives as a happy ending to her memoir, the reader perceives as deeply sad. Thurman's Modernist Burlesque is complete.

\section{Conclusion}

The conclusion to this study seems to be multiple, and somewhat unexpected. Based on the digital analyses of Peggy Hopkins Joyce's memoir, is no reason to believe Basil Woon had anything to do with their composition; on the contrary, every analysis performed on the text in combination with Anita Loos' Gentlemen Prefer Blondes and But Gentlemen Marry Brunettes returns the some result: that Joyce's memoir was written by Anita Loos. This means the book was either written by Anita Loos (which given the circumstances was highly unlikely), or that the writer of Peggy Hopkins Joyce's memoir aped Anita Loos' style to such a degree that it is able to mislead stylometric software. There is also, of course, the possibility that Peggy Hopkins Joyce wrote the book herself, and in doing so, mimicked the style Anita Loos used to mimic her. This raises the interesting question, beyond the scope of this study, as to how stylometric analysis manages texts that are meant to disguise their author intentionally, or to ape another author's style intentionally.

The inconclusiveness of the digital analysis required me to look at other possibilities for analyzing author attribution. To my mind, the most likely candidate is Wallace Thurman; moreover, a reading of the text as a work of satire in the style of Modernist Burlesque, one frequently used by Harlem Renaissance satirists, of which Thurman was one of the most prominent, brings fruitful results. A neglected book of celebrity gossip and fluff reveals unexpected literary and philosophic subtleties when read as the work of someone coming from such a radically different economic, social, philosophical, artistic and racial perspective in the heady jazz age years of the 1920s.

\section{Works Cited}

"Basil Woon, 80, Journalist, Dies." The New York Times, June 5, 1974, p. 46. "Macaulay Company Records." Special Collections. Ohio State University. https:// library.osu.edu/collections/spec.rare.cms.0296/collection-inventory. Accessed May 5, 2020. 
“The Week of a New Yorker." The Brooklyn Daily Eagle, Feb 17, 1930, vol. 90, no. 47 , p. 21.

Beauchamp, Cari. "Hollywood Success and International Fame 1915-1930." Anita Loos Rediscovered: Film Treatments and Fiction by Anita Loos, Creator of Gentlemen Prefer Blondes. University of California Press, 2003, pp. 37-125.

Carey, Gary. Anita Loos: A Biography. Knopf, 1988.

Dickson-Carr, Darryl. Spoofing the Modern: Satire in the Harlem Renaissance. University of South Carolina Press, 2015.

Eder, Maciej, Jan Rybicki, and Mike Kestemont. Stylometry with R: A Package for Computational Text Analysis. $R$ Journal, vol. 8, no. 1, pp. 107-121. https://journal.r-project.org/archive/2016/RJ-2016-007/index.html.

Gamerman, Ellen. "Data Miners Dig Into 'Go Set a Watchman." Wall Street Journal, July 16, 2015. https://www.wsj.com/articles/data-miners-diginto-go-set-a-watchman-1437096631.

Hughes, Langston. "Harlem Literati in the Twenties." Saturday Evening Review, June 22, 1940, pp. 13-14.

The Big Sea. Farrar, Strauss and Giroux, 1993.

Hurston, Zora Neale. "How It Feels to be Colored Me." The World Tomorrow, May 1928, pp. 215-216.

Jockers, Matthew L. Macroanalysis: Digital Methods and Literary History. University of Illinois Press, 2013.

Joula, Patrick. "Rowling and 'Galbraith': An Authorial Analysis." Language Log, University of Pennsylvania. https://languagelog.ldc.upenn.edu/ $\mathrm{nll} / \mathrm{p}=5315$.

Joyce, Peggy Hopkins. Men, Marriage and Me. The Macaulay Company, 1930.

Mencken, H.L. The Philosophy of Friedrich Nietzsche. Luce and Company, 1913. Nietzsche, Friedrich. Beyond Good and Evil, translated by Helen Zimmern, The Modern Library, 1917.

Nugent, Richard Bruce. "Smoke, Lilies and Jade." Fire!!, vol. 1, no. 1, pp. 33-39.

Moretti, Franco. Distant Reading. Verso Books, 2005.

Rosenblum, Constance. "Personal Correspondence." Email, May 17, 2018.

Gold Digger: The Outrageous Life and Times of Peggy Hopkins Joyce, Metropolitan Books, 2015.

Singh, Amritjit, and Daniel M. Scott III. "Chronology." The Collected Writings of Wallace Thurman. Rutgers University Press 2003, pp. xvii-xviii.

Thurman, Wallace. "Notes on a Stepchild." The Collected Writings of Wallace Thurman. Rutgers University Press 2003, pp. 235-240.

van Notten, Eleonore. Wallace Thurman's Harlem Renaissance. Rodopi, B.V., 1994.

Weer, William. "Peggy Hopkins Joyce Turns Author, Tells All in Book on Marriages." Brooklyn Daily Eagle, January 30, 1930, vol. 90, no. 29, p. 19. 


\section{APPENDIX A: CORPUS OF BOOKS}

Arnim Enchanted - The Enchanted April, Elizabeth von Anrim (1922)

Asquith_Autobiography - The Autobiography of Margot Asquith, Margot Asquith (1921)

Atherton_Oxen - Black Oxen, Gertude Atherton (1923)

Atherton_Sisters - The Sisters-in-Law, Gertrude Atherton (1921)

Buck_Earth - The Good Earth, Pearl S. Buck (1931)

Bok_Americanization - The Americanization of Edward Bok, Edward Bok (1923)

Burnett_Coombe - The Head of the House of Coombe, Frances Hodgson Burnett (1922)

Canfield_Brimming - The Brimming Cup, Dorothy Canfield (1921)

Cather_Shadows - Shadows on the Rock, Willa Cather (1931)

Curwood_Valley - The Valley of Silent Men, James Oliver Curwood (1920)

Dekobra_Pigalle - Midnight on the Place Pigalle, Maurice Dekobra (1932)

Dekobra_Venus - Venus on Wheels, Maurice Dekobra (1930)

EPorter_Marie - Mary Marie, Eleanor H. Porter (1920)

Ferber_Cimmaron - Cimmaron, Edna Ferber (1929)

Fitzgerald_Amory - This Side of Paradise, F Scott Fitzgerald (1920)

Fitzgerald_Damned, The Beautiful and the Damned, F. Scott Fitzgerald (1922)

Gray_Forest - The Man of the Forest, Zane Gray (1920)

Gray_Rider - The Mysterious Rider, Zane Gray (1921)

Hull_Sheik - The Sheik, E.M. Hull (1921)

Hurst_Stardust - Stardust: A Story of an American Girl, Fanny Hurst (1921)

Hurston_Eyes - Their Eyes Were Watching God, Zora Neale Hurston (1937)

Hurston_Jonah - Jonah's Gourd Vine, Zora Neale Hurston (1933)

Hutchinson_Freedom - This Freedom, A.S.M. Hutchinson (1922)

Hutchinson_Winter - If Winter Comes, A.S.M. Hutchinson (1921)

Larsen_Passing - Passing, Nella Larsen (1929)

Lewis_Babbitt - Babbitt, Sinclair Lewis (1922)

Lewis_Main - Main Street, Sinclair Lewis (1920)

Loos_Blondes - Gentlemen Prefer Blondes, Anita Loos (1925)

Loos_Brunettes - But Gentlemen Marry Brunettes, Anita Loos (1927)

Mitchell_Gone - Gone with the Wind, Margaret Mitchell (1936)

Norris_Piper - Harriet and the Piper, Kathleen Norris (1920)

Rineheart_Breaking - The Breaking Point, Mary Roberts Rineheart (1923)

Rineheart_Poor - A Poor Wise Man, Mary Roberts Rineheart (1920)

Tarkington_Julia - Gentle Julia, Booth Tarkington (1922)

Thurman_Berry - The Blacker the Berry, Wallace Thurman (1929)

Thurman_Infants - Infants of the Spring, Wallace Thurman (1932)

Unknown_Marriage - Men Marriage and Me, Peggy Hopkins Joyce (1930)

Walpole_Rogue - Rogue Herries, Hugh Walpole (1930)

Wharton_Innocence - Age of Innocence, Edith Wharton (1920)

Wilder_Andros - The Woman of Andros, Thornton Wilder (1930)

Woon_Arizona - Arizona's Yesterday, John Cady, rewritten by Basil Woon (1915) 
Woon_Cocktail - When It's Cocktail Time in Cuba, Basil Woon (1928)

Woon_Bernhardt -Sarah Bernhardt as I Knew Her: The Memoirs of Madame Pierre Berton as Told to Basil Woon, Basil Woon (1923) 